\title{
Research and teaching writing
}

\author{
Steve Graham ${ }^{1,2} \cdot$ Rui A. Alves ${ }^{3}$
}

Accepted: 29 June 2021 / Published online: 12 July 2021

(C) The Author(s), under exclusive licence to Springer Nature B.V. 2021

\begin{abstract}
Writing is an essential but complex skill that students must master if they are to take full advantage of educational, occupational, and civic responsibilities. Schools, and the teachers who work in them, are tasked with teaching students how to write. Knowledge about how to teach writing can be obtained from many different sources, including one's experience teaching or being taught to write, observing others teach writing, and advise offered by writing experts. It is difficult to determine if much of the lore teachers acquire through these methods are effective, generalizable, or reliable unless they are scientifically tested. This special issue of Reading \& Writing includes 11 writing intervention studies conducted primarily with students in the elementary grades. It provides important new information on evidence-based writing practices.
\end{abstract}

Keywords Writing · Writing intervention · Evidence-based · Elementary grades · Writing instruction

\section{Research and teaching writing}

There are many different ways that teachers can learn about how to teach writing. One way of acquiring such knowledge is by teaching this skill to others. As teachers apply different instructional procedures, they form judgments about the value and efficacy of these practices. In essence, they learn by doing (Graham, 2018).

A second way teachers learn about how to teach writing is by observing others and learning from them (Graham, 2018). Teachers likely remember some of the instructional methods used by those who taught them to write (e.g., teachers, mentors, parents, guardians, and peers). They may in turn adopt some of these practices

Rui A. Alves

ralves@fpce.up.pt

1 Arizona State University, Tempe, Arizona, USA

2 Australian Catholic University, Brisbane, Australia

3 University of Porto, Porto, Portugal 
when they teach their own students. This may be particularly true for instructional practices they considered effective.

Teachers can gain additional insight into teaching writing by observing and absorbing insights offered by others who have taught writing or studied how to teach it. This includes knowledge acquired from instructors teaching literacy and writing courses as well as experts offering advice on writing instruction at conferences, through workshops, podcasts, or other forms of information sharing. Teachers may also learn about teaching writing by discussing this topic with their peers or observing them as they teach writing.

A third source of knowledge that teachers can access are published materials about how to teach writing. This includes textbooks and articles on the subject, curriculum guides, commercial materials, and position statements from professional organizations to provide just a few examples. These resources can further involve digital sources such as videos demonstrating how to apply specific writing procedures, experts promoting specific teaching techniques, or web sites devoted to writing instruction.

\section{The concern}

Given all of the possible knowledge sources teachers can access or experience, there is an abundance of information, recommendations, and teaching materials on how to teach writing that is available to teachers. This blessing experiences at least one serious limitation. Too often, there is limited, circumscribed, or no evidence that the proffered advice, know-how, or wisdom works. There are many claims about what is effective, but too little proof. Unfortunately, this observation applies to much of the lore that teachers acquire about writing instruction.

Teaching lore mainly involves writing practices teachers experienced when they learned to write, instructional practices teachers develop and apply with their students, writing practices they see other teachers apply, and teaching practices promoted by experts (Graham \& Harris, 2014). While we have no doubt that teachers and experts possess considerable knowledge and insight about how to teach writing, basing the teaching of this complex skill on such lore alone is risky.

Why is this the case? One reason is that it is difficult to determine which aspects of teaching lore are valid. For example, there are many things a teacher does while teaching writing. When their students' writing improves, they may attribute this change to specific procedures they applied. While this evaluation may be correct, it is also possible that this judgment is incorrect or only applies to some students or to a procedure in a given context.

Teachers are not the only ones who can succumb to such selective bias. Specific teaching lore promoted by writing experts are also susceptible to misinterpretation in terms of their effectiveness. To illustrate, writing experts can overestimate the impact of favored instructional methods, forming judgments consistent with their philosophical views on writing development or instruction. For instance, proponents of the whole language approach to learning to read and write believed that writing and reading develop naturally just like oral language (Goodman, 1992). Consistent with 
these beliefs, they championed an approach to literacy instruction based on the use of informal teaching methods (e.g., reading and writing for real purposes), while at the same time deemphasizing explicitly and systematically teaching students foundational writing and reading skills and strategies (Graham \& Harris, 1997). Instead, these skills are only taught when the need arises, mostly through short mini-lessons. Advocates for whole language frequently promoted the effectiveness of this two-pronged approach (Begeron, 1990), without providing much in the way of empirical evidence that it was effective, or perhaps even more importantly, that it was as effective as other alternatives such as reading and writing programs that emphasized reading and writing for real purposes, coupled with systematic and explicit skills and strategy instruction (Graham \& Harris, 1994). Even for fundamental writing skills such as spelling, there is considerable evidence that both informal teaching and explicit instruction are effective (Graham, 2000; Graham \& Santangelo, 2014), while whole language approaches are fundamentally misguided about what is written language (Liberman, 1999).

Whole language is not the only approach to teaching writing that has suffered from questionable claims about its effectiveness. Even the venerable Donald Graves was guilty of this to some degree with the process approach to writing that he supported and advocated (see Smagorinski, 1987). The evidence he offered in support of his favored approach to teaching writing relied in large part on testimonials and exemplar writing of selected students, presenting a potentially overly optimistic assessment of this approach. This is not to say that the process approach is ineffective, as there is now considerable empirical evidence supporting the opposite conclusion (Sandmel \& Graham, 2011). Instead, this example illustrates that adopting whole cloth even highly popular and widely used teaching lore without careful consideration of its effectiveness and the evidence available to support it can be risky. The lack of evidence or the type of evidence provided can make it extremely difficult for teachers or other interested parties to determine if the testimonials or evidence used to support specific teaching lore in writing are representative or atypical.

A third issue that makes some teaching lore risky is that it may be based on the experience of a single or a very small number of teachers. As an example, this can occur for knowledge a teacher acquires as a result of his or her experience teaching writing. The teaching practice(s) may in fact be effective for the students in this teacher's classroom, but they may not be effective when applied by another teacher or with different students. Until this proposition is tested, there is no way to determine if this teaching lore will produce reliable results when applied more broadly.

As these concerns demonstrate, the validity, generalizability, and replicability of instructional practices based on teaching lore are uncertain. This is not to devalue what teachers or experts know, but to demonstrate the limits of this knowledge.

\section{Evidence-based writing practices}

The concerns about the value of teaching lore raised above raises the question: How should the structure and details of writing instruction be determined? The solution that we recommend is to take an evidence-based practice approach to both enhance teachers' knowledge and develop writing instruction. Starting with medicine in 
the 1990s, and spreading quickly to psychology, informational science, business, education, and a host of other disciplines, this movement promoted the idea that practitioners in a field should apply the best scientific evidence available to make informed and judicious decisions for their clients (Sackett et al., 1996). The basic assumption underlying this approach is that the findings from research can positively impact practice. The evidence-based practice movement was a reaction to practitioners basing what they did almost strictly on tradition and lore, without scientific evidence to validate it.

One reason why this represents a positive step forward in education and the teaching of writing is that instructional practices based on high quality intervention research addresses the three issues of concern we raised about teaching lore. First, high quality intervention studies address the issue of validity. They are designed specifically to isolate the effects of a specific instructional practice or set of instructional practices. They provide systematically gathered evidence on whether the instructional practices tested produced the desired impact. They further apply methodological procedures to rule out alternative explanations for observed effects. Second, high quality intervention studies address issues of generalizability by describing the participants and the context in which the practice was applied, and by using statistical procedures to determine the confidence that can be placed in specific findings. Three, they address the issue of replicability, as the replication of effects across multiple situations is the hall mark of scientific testing (Graham \& Harris, 2014).

Another reason why the evidence-based approach represents a positive step forward in terms of teaching writing is that the evidence gathered from high quality intervention studies can provide a general set of guidelines for designing an effective writing program. Graham et al. (2016) created such a roadmap by drawing on three sources of scientific evidence: true-and quasi- experimental writing intervention studies, single-case design studies, and qualitative studies of how exceptional literacy teachers taught writing (see also Graham \& Harris, 2018). They indicated that the scientific evidence from these three sources supports the development of writing programs that include the following. Students write frequently. They are supported by teachers and peers as they write. Essential writing skills, strategies, and knowledge are taught. Students use word processors and other twenty-first century tools to write. Writing occurs in a positive and motivating environment. Writing is used to support learning. Based on several recent meta-analyses of high quality intervention studies (Graham, et al., 2018a, b; Graham, et al., 2018a, b), Graham now recommends that the evidence also supports connecting writing and reading instruction (Graham, 2019, 2020).

A third reason why the evidence-based approach is a positive development is that it provides teachers with a variety of techniques for teaching writing that have been shown to be effective in other teachers' classes and in multiple situations. While this does not guarantee that a specific evidence-based practices is effective in all situations, a highly unlikely proposition for any writing practice, it does provide teachers with instructional procedures with a proven track record. This includes, but is not limited to (Graham \& Harris, 2018; Graham et al., 2016):

Setting goals for writing. 
Teaching general as well as genre-specific strategies for planning, revising, editing, and regulating the writing process.

Engaging students in prewriting practices for gathering, organizing, and evaluation possible writing contents and plans.

Teaching sentence construction skills with sentence-combining procedures.

Providing students with feedback about their writing and their progress learning new writing skills.

Teaching handwriting, spelling, and typing.

Increasing how much students write; analyzing and emulating model texts.

Teaching vocabulary for writing.

Creating routines for students to help each other as they write.

Putting into place procedures for enhancing motivation.

Teaching paragraph writing skills.

Employing technology such as word processing that makes it easier to write.

It is also important to realize that an evidence-based approach to writing does not mean that teachers should abandon the hard-earned knowledge they have acquired through their experiences as teachers or learners. The evidence-based movement emphasizes that teachers contextualize knowledge about teaching writing acquired through research with their own knowledge about their students, the context in which they work, and what they know about writing and teaching it (Graham et al., 2016). When applying instructional practices acquired through research as well as teaching lore, we recommend that teachers weigh the benefits, limitations, and possible harm that might ensue as a consequence of applying any teaching procedure. Once a decision is made to apply a specific practice, it is advisable to monitor its effectiveness and make adjustments as needed.

Finally, while the scientific testing of writing practices has provided considerable insight into how writing can be taught effectively, it is not broad, deep, or rich enough to tell us all we need to know about teaching writing. It is highly unlikely that this will ever be the case. We operate on the principle that there is no single best method for teaching writing to all students, nor is it likely that science will provide us with formulas to prescribe exactly how writing should be taught to each student individually. Writing, learning, children, and the contexts in which they operate are just too complex to make this a likely consequence of the evidence-based movement. As a result, we believe that the best writing instruction will be provided by teachers who apply evidence-based practices in conjunction with the best knowledge they have acquired as teachers and learners, using each of these forms of knowledge in an intelligent, judicious, and critical manner.

Over time, we anticipate that evidence-based practices will play an ever increasing role in the process described above. This is inevitable as our knowledge about evidence-based writing practices expands. This brings us to the purpose of this special issue of Reading \& Writing: An Interdisciplinary Journal. This special issue presents 11 writing intervention studies focusing almost exclusively with students in the elementary grades. These studies were conducted in 
Europe and the United States, and they replicate and extend prior research conducted with young developing writers.

\section{The special issue}

Perhaps the most tested writing instructional practice of all time, and the one yielding the largest effects sizes (Graham et al., 2013), is the Self-regulated Strategy Development (SRSD) model developed by Karen Harris (see Harris et al., 2008 for a description of this approach). Several studies in the current special issue tested specific iterations of the use of the SRSD model as a means for teaching writing to elementary grade students. Collins and her colleagues examined the effectiveness of teaching third grade students in the United States task specific strategies for planning and drafting expository essays using information from social studies text using this model. This instruction enhanced the quality of students' texts and resulted in improvement on a norm-referenced measure of writing where students identified their favorite game and provided reasons why this was the case.

In a second SRSD study conducted with second and third grade children in Spain, Salas and her colleagues examined if teaching planning and drafting strategies for writing an opinion essay was equally effective with children from more and less disadvantaged backgrounds. SRSD was equally effective in improving the opinion writing of children from both backgrounds, but carryover effects to reading comprehension (a skill not taught in this study) only occurred for students from less disadvantaged backgrounds.

A third study by Rosario and his colleagues involved a secondary analysis of data from an investigation in Portugal where third grade students were taught to write narratives using SRSD procedures and a story writing tool they developed. Their reanalysis focused on students experiencing difficulties learning to write showing that they differed in their approach and perceptions of teacher feedback. The majority of these children were able to use the feedback provided by their teacher and viewed it as helpful.

A fourth investigation by Hebert and his colleagues taught fourth grade students in the United States to write informational text using five text structures (description, compare/contrast, sequence of events, problem-solution, and cause effect). While the authors did not indicate they used SRSD to teach these strategies, the teaching methods mirrored this approach. In any event, the instruction provided to these children enhanced how well they wrote all five of these different kinds of text. These effects, however, did not generalize to better reading performance.

Lopez and her colleagues in Spain examined three approaches to improving sixth grade students' writing. Students in all three conditions were taught how to set communicative goals for their writing. Students in one treatment condition were taught a strategy for revising. Students in a second treatment condition observed a reader trying to comprehend a text and suggesting ways it might be improved. Control students continued with the goal setting procedures. Students in both treatment conditions improved their writing and revising skills more than control students, but there were no differences between these two treatments. 
In another Spanish study conducted by Rodriguez-Malaga and colleagues, the impact of two different treatments on the writing of fourth grade students was examined. One treatment group learned how to set product goals for their writing, whereas the other writing treatment group learned how to set product goals and strategies for planning compare/contrast texts. Only the students in the product goal and planning strategy treatment evidenced improved writing when compared to control students.

Philippakos and Voggt examined the effectiveness of on-line practice-based professional development (PBPD) for teaching genre-based writing strategies. Eightyfour second grade teachers were randomly assigned to PBPD or a no-treatment control condition. Treatment teachers taught the genre-based writing strategies with high fidelity and rated PBPD positively. Even more importantly, their students writing evidenced greater improvement than the writing of students in control teachers' classes.

Walter and her colleagues in England examined the effectiveness of two writing interventions, sentence combining and spelling instruction, with 7 to 10 year old children experiencing difficulties learning to write. As expected, sentence combining instruction improved sentence construction skills, but even more importantly, these researchers found that the degree of improvements in sentence writing was related to students' initial sentence, spelling, and reading skills.

In another study focused on improving students' sentence construction skills, Arfé and her colleagues in Italy examined the effectiveness of an oral language intervention to improve the sentence construction skills of fifth and tenth grade students. This oral treatment did enhance the sentence writing skills of the younger fifth grade students. This study provides needed evidence that interventions aimed at improving oral language skills transfer to writing.

Chung and his colleagues in the United States examined if sixth grade students' writing can be improved through self-assessment, planning and goal setting, and self-reflection when they revised a timed, on-demand essay. These students as well as students in the control condition were also taught how to revise such an essay. Treatment students evidenced greater writing gains, and were more confident about their revising capabilities than control students.

Lastly, Graham and his colleagues in the United States examined if the revising behavior of fourth grade students experiencing difficulties with writing can be enhanced through the use of revising goals that focused attention on making substantive when revising stories (e.g., change the setting of the story). Applying such goals across four stories had a positive effect on the revising behavior of these students when these goals were not in effect, resulting in more text-level revisions, more revisions that changed the meaning of text, and more revisions rated as improving text.

The 11 intervention studies in this special issue of Reading \& Writing are particularly noteworthy for several reasons. One, some of these studies $(n=4)$ concentrated on improving students' skills in writing informational and expository text. This is an area that has not received enough attention in existing writing literature. Two, enhancing students' revising was the goal of multiple studies $(n=4)$. Again, too little attention has been given to this topic with either younger or older students. Three, it was especially gratifying to see that a pair of studies 
examined how to enhance sentence writing skills. This has been a neglected area of writing research since the 1980s. Four, multiple studies focused on improving the writing of students who experienced difficulties learning to write $(n=3)$. This is an area where we need much more research if we are to maximize these students' writing success. Finally, more than half of the studies in this special issue $(n=6)$ were conducted in Europe, with the other half conducted in the United States. It is important to examine if specific writing treatments are effective in different social, cultural, political, institutional, and historical context (Graham, 2018), as was done with the four studies that applied SRSD to teach students strategies for writing.

We hope you enjoy the studies presented here. We further hope they serve as a catalyst to improve your own research if you are a writing scholar or your teaching if you are a practitioner.

\section{References}

Begeron, B. (1990). What does the term whole language mean? constructing a definition from the literature. Journal of Reading Behavior, 22, 301-329. https://doi.org/10.1080/10862969009547716

Goodman, K. (1992). I didn't found whole language. The Reading Teacher, 46, 188-199.

Graham, S. (2000). Should the natural learning approach replace traditional spelling instruction. Journal of Educational Psychology, 92, 235-247. https://doi.org/10.1037/0022-0663.92.2.235

Graham, S. (2018). The writer(s)-within-community model of writing. Educational Psychologist, 53, 258-279. https://doi.org/10.1080/00461520.2018.1481406

Graham, S. (2019). Changing how writing is taught. Review of Research in Education, 43, $277-303$. https://doi.org/10.3102/0091732x18821125

Graham, S. (2020). The sciences of reading and writing must become more fully integrated. Reading Research Quarterly, 55(S1), S35-S44.

Graham, S., \& Harris, K. R. (1997). It can be taught, but it does not develop naturally: myths and realities in writing instruction. School Psychology Review, 26, 414-424. https://doi.org/10.1080/02796015. 1997.12085875

Graham, S., \& Harris, K. R. (2014). Conducting high quality writing intervention research: twelve recommendations. Journal of Writing Research, 6(2), 89-123. https://doi.org/10.17239/jowr-2014.06. 02.1

Graham, S., \& Harris, K. R. (2018). Evidence-based writing practices: A meta-analysis of existing metaanalyses. In R. Fidalgo, K. R. Harris, \& M. Braaksma (Eds.), Design Principles for teaching effective writing: Theoretical and empirical grounded principles (pp. 13-37). Brill Editions.

Graham, S., Harris, K. R., \& Chambers, A. (2016). Evidence-based practice and writing instruction. In C. MacArthur, S. Graham, \& J. Fitzgerald (Eds.), Handbook of Writing Research (2: 211-226). NY; Guilford.

Graham, S., Harris, K. R., \& McKeown, D. (2013). The writing of students with LD and a meta-analysis of SRSD writing intervention studies: Redux. In L. Swanson, K. R. Harris, \& S. Graham (Eds.), Handbook of Learning Disabilities (2nd ed., pp. 405-438). Guilford Press.

Graham, S., \& Harris, . (1994). The effects of whole language on writing: a review of literature. Educational Psychologist, 29, 187-192. https://doi.org/10.1207/s15326985ep2904_2

Graham, S., Liu, K., Aitken, A., Ng, C., Bartlett, B., Harris, K. R., \& Holzapel, J. (2018a). Effectiveness of literacy programs balancing reading and writing instruction: a meta-analysis. Reading Research Quarterly, 53, 279-304. https://doi.org/10.1002/rrq.194

Graham, S., Liu, K., Bartlett, B., Ng, C., Harris, K. R., Aitken, A., Barkel, A., Kavanaugh, C., \& Talukdar, J. (2018b). Reading for writing: a meta-analysis of the impact of reading and reading instruction on writing. Review of Educational Research, 88, 243-284. https://doi.org/10.3102/0034654317 746927 
Graham, S., \& Santangelo, T. (2014). Does spelling instruction make students better spellers, readers, and writers? a meta-analytic review. Reading \& Writing: An Interdisciplinary Journal, 27, 1703-1743. https://doi.org/10.1007/s11145-014-9517-0

Harris, K. R., Graham, S., Mason, L., \& Friedlander, B. (2008). Powerful writing strategies for all students. Baltimore, MD: Brookes.

Liberman, A. M. (1999). The reading researcher and the reading teacher need the right theory of speech. Scientific Studies of Reading, 3(2), 95-111. https://doi.org/10.1207/s1532799xssr0302_1

Sackett, D., Rosenberg, W., Gray, J., Haynes, R., \& Richardson, W. (1996). Evidence based medicine: what it is and what it isn't. British Medical Journal, 312, 71-72. https://doi.org/10.1136/bmj.312. 7023.71

Sandmel, K., \& Graham, S. (2011). The process writing approach: a meta-analysis. Journal of Educational Research, 104, 396-407. https://doi.org/10.1080/00220671.2010.488703

Smagorinski, P. (1987). Graves revisited: a look at the methods and conclusions of the New Hampshire study. Written Communication, 4, 331-342. https://doi.org/10.1177/0741088387004004001

Publisher's Note Springer Nature remains neutral with regard to jurisdictional claims in published maps and institutional affiliations. 